\title{
Chinese companion animal caretakers' attachment influences their attribution of emotions to their animals
}

Citation for published version (APA):

Su, B., \& Martens, P. (2022). Chinese companion animal caretakers' attachment influences their attribution of emotions to their animals. Society and Animals, 30(2), 131-150.

https://doi.org/10.1163/15685306-12341550

Document status and date:

Published: 01/03/2022

DOI:

10.1163/15685306-12341550

Document Version:

Publisher's PDF, also known as Version of record

Document license:

Taverne

Please check the document version of this publication:

- A submitted manuscript is the version of the article upon submission and before peer-review. There can be important differences between the submitted version and the official published version of record.

People interested in the research are advised to contact the author for the final version of the publication, or visit the DOI to the publisher's website.

- The final author version and the galley proof are versions of the publication after peer review.

- The final published version features the final layout of the paper including the volume, issue and page numbers.

Link to publication

\footnotetext{
General rights rights.

- You may freely distribute the URL identifying the publication in the public portal. please follow below link for the End User Agreement:

www.umlib.nl/taverne-license

Take down policy

If you believe that this document breaches copyright please contact us at:

repository@maastrichtuniversity.nl

providing details and we will investigate your claim.
}

Copyright and moral rights for the publications made accessible in the public portal are retained by the authors and/or other copyright owners and it is a condition of accessing publications that users recognise and abide by the legal requirements associated with these

- Users may download and print one copy of any publication from the public portal for the purpose of private study or research.

- You may not further distribute the material or use it for any profit-making activity or commercial gain

If the publication is distributed under the terms of Article $25 \mathrm{fa}$ of the Dutch Copyright Act, indicated by the "Taverne" license above, 


\title{
Chinese Companion Animal Caretakers' Attachment Influences their Attribution of Emotions to their Animals
}

\author{
Bingtao Su \\ Department of Sociology, Shandong University, Jinan, China \\ subingtao@sdu.edu.cn
}

\begin{abstract}
Pim Martens
International Centre for Integrated Assessment and Sustainable

Development (ICIS), Maastricht University, The Netherlands
\end{abstract}

\begin{abstract}
It is well-documented that in developed countries, companion animal caretakers often show strong attachments to their animals. However, very little research has incorporated caretakers' attachment to companion animals in developing countries such as China. This research analyzed the correlation between the attachment level of Chinese dog and cat caretakers and their attribution of emotions to their animals. The results indicated a trend that respondents frequently attributed primary emotions to companion animals rather than secondary emotions. Respondents who had frequent and multiple interactions with their companion animals scored higher on the Pet Bonding Scale (PBS). The degree of attachment significantly influenced caretakers' (particularly female caretakers') attribution of responsive emotions to companion animals. This study is one of the first to investigate the role of attachment in emotion attribution in an under-researched population and can therefore act as a baseline for follow-up research.
\end{abstract}

\section{Keywords}

companion animals - emotions - dogs - cats - Pet Bonding Scale 


\section{Introduction}

A better understanding of nonhuman animal emotion is highly desirable in the disciplines of animal welfare science and evolutionary psychology (Waller \& Micheletta, 2013). Previous literature has suggested that emotions can be classified into primary and secondary ones (Becker-Asano \& Wachsmuth, 2010; Marg, 1995). Primary emotions are supposed to be innate and elicited as an immediate response to a stimulus (Becker-Asano \& Wachsmuth, 2010), while secondary emotions are the product of cognitive processing (Becker \& Wachsmuth, 2006). A characteristic of primary emotions (e.g., fear, anger, joy, sadness, surprise, and disgust) is that they can be perceived across a wide range of animal species according to their facial displays and muscle movements (Darwin, 1965). In contrast, secondary emotions (e.g., shame, jealousy, disappointment, and compassion) are generally restricted to relatively mature humans and perhaps other primates (Morris, Doe, \& Godsell, 2008; Preston \& De Waal, 2002).

Over the past few decades, a growing number of studies have been conducted in developed countries on people's attribution of emotions to animals and people's attitudes toward animals (Anderson, 2007; Martens, Enders-Slegers, \& Walker, 2016; Walker, McGrath, Handel, Waran, \& Phillips, 2014; Walsh, 2009). However, studies into people's degree of attachment and their attribution of emotions to animals in countries such as China remain in the initial stages of development. In Chinese culture, particularly in Confucianism, animals have been respected as an essential part of human society since they are the main source of food, clothes, and health care for the majority of the population. Some animals even represent important values in Chinese culture. For instance, dogs are usually associated with loyalty and faithfulness (Pręgowski, 2016).

Animal cruelty — such as suffering, deprivation, or killing of animals - is regarded as morally problematic (Blakeley, 2003). However, in Chinese traditions, animals also play a key role in formal ritual activities and divination. For example, suckling pigs have been used as gifts to express gratitude and respect to the spirits of mountains and rivers (Blakeley, 2003). Therefore, animals can be sacrificed for human beings, although Confucianism theories highlight the importance of animal protection. Daoism, a native folk religion in China, advocates morals and universal love. In their doctrines, humans are encouraged to learn from nonhuman animals (Li \& Davey, 2013). Moreover, humans should protect animals, as animals have the same feelings as humans. This probably reflects earlier recognition of animal emotion in China. Additionally, as one of the most important religions in China, Buddhism emphasizes the equality of all living creatures, including humans and nonhuman animals (Barber, 2015; 
Li \& Davey, 2013). It is therefore plausible that people's attitudes toward animals might be positive in traditional China (Walsh, 2009).

However, as a result of the collapse of the economy, animal welfare was overlooked during the first forty years of modern China. This situation was unfortunate because animal welfare standards in China were much lower than those of their Western counterparts (Davey, 2006). Therefore, animal cruelty in China has been commonly reported, which even led to worldwide criticisms. In 1988, the wildlife protection law of the People's Republic of China was enacted, which represented a positive step toward animal protection and animal welfare, although until very recently, "animal welfare" had been a wholly novel concept to most of the Chinese people (D'Silva \& Turner, 2012). Notably, in recent years, the Chinese booming economy and the rising societal awareness of human rights had begun to stimulate people's consideration of animal rights and welfare. However, awareness of animal emotions and human-animal attachment in China appears to be less common than that in Western countries. In this paper, we examine people's attributions of emotions and their feelings of attachment to animals in contemporary China.

Research into human-animal relationships has demonstrated that companion animal caretakers are more likely to believe in the existence of emotional experiences in their animals than non-caretakers (Walker, McGrath, Handel, et al., 2014). Companion animal caretakers often attribute more complex emotions to their dogs, while attributing more basic emotions to cats (Darwin, 1965; Martens et al., 2016). A companion animal's age negatively influences the mutual emotional interactions between the animal and caretaker, because old animals' lower quality of life often leads to diminished emotional bonds (Marinelli, Adamelli, Normando, \& Bono, 2007).

Human demographics, such as gender and age, were also considered as influential factors for the attribution of emotions to animals. For instance, women generally have higher levels of belief in the mental abilities of animals than men (Knight, Nunkoosing, Vrij, \& Cherryman, 2003), while younger people more frequently attribute some emotions (e.g., anger, fear) to their companion animals than older people (Martens et al., 2016). These studies reveal that companion animal ownership, animal species, and the demographics of humans and animals can influence the attribution of emotions in developed countries. However, very little research analyzed how people's degree of attachment influences their attribution of emotions to animals (Marinelli et al., 2007; Martens et al., 2016). These studies were conducted in developed countries where people already have extensive awareness of animal welfare. We question whether a low degree of attachment as well as limited attribution of emotions would be present in a country where the awareness of animal 
welfare is poor. We selected China to be representative of such a country because public awareness of animal welfare is supposed to be low (Davey, 2006; Li \& Davey, 2013).

This research aimed at investigating the Chinese companion animal caretakers' attribution of their animals' emotions, as well as how their degree of attachment (measured by the Pet Bonding Scale: PBS) might correlate with their attribution of emotions to their companion cats or dogs. We also explored the knowledge of demographic variables (both human and animals) that underpin companion animal caretakers' attribution of emotions to their animals in contemporary China, as diverse factors influence people's attachment to their animals in developed countries (Martens et al., 2016; Walsh, 2009; Woodward \& Bauer, 2007).

\section{Materials and Methods}

\section{Participants}

In total, 503 completed surveys were received. Respondents' basic information is presented in table 1 .

\section{Materials}

Using The Emotions of Pets Questionnaire (Martens et al., 2016), we wanted to reveal any correlation between Chinese companion animal caretakers' attribution of emotions and their degree of attachment to their animals. Notably, the use of the term "attachment" to companion animals is a debatable issue (Kobak, 2009, p. 447), but in this paper, the "attachment" (measured and established by P BS score) means the emotional bonds between companion animals and their caretakers.

Respondents were asked to supply their basic information (e.g., age, gender, household composition, and household income), the information about their companion animals' basic characteristics (e.g., species, breed, gender, size, and age), as well as their husbandry practices (e.g., How often and how much do you feed your dog or cat? Where does your dog/cat sleep? Who is taking care of your $\mathrm{dog} /$ cat when you are not around?).

The PBS (Cronbach's alpha $=0.949)$ (Angle, Blumentritt, \& Swank, 1994), which includes 25 questions, was used to assess a caretaker's degree of attachment to their companion animal. Respondents were asked to respond to statements using the five-point $\mathrm{PBS}$, ranging from $\mathrm{o}$ (strongly disagree) to 4 (strongly agree). The sum of PBS scores indicates the level of caretakers' attachment to 
$\mathrm{N}(\%)$

\begin{tabular}{|c|c|}
\hline Animal species & $\operatorname{Dog}=373(74.2) ;$ Cat $=130(25.8)$. \\
\hline Gender & Male $=240(47 \cdot 7) ;$ Female $=263\left(5^{2 \cdot 3}\right)$ \\
\hline $\begin{array}{l}\text { Age }(M=38.6 \\
\text { SD }=11.5)\end{array}$ & $\begin{array}{l}18-29 \text { years }=118(23.5) ; 30-39 \text { years }=164(32.6) ; 40-49 \text { years }=116 \\
(23.1) ; 50-59 \text { years }=80(15.9) ; 60 \text { years and older }=25(5.0)\end{array}$ \\
\hline $\begin{array}{l}\text { Organization } \\
\text { participation }\end{array}$ & $\begin{array}{l}\text { Improving the welfare of animals }=259(51.5) \text {; Conservation of } \\
\text { the natural environment }=35^{1}(69.8) \text {; Improving human rights or } \\
\text { health }=25^{2}\left(5^{0.1}\right) .\end{array}$ \\
\hline $\begin{array}{l}\text { Household } \\
\text { composition }\end{array}$ & $\begin{array}{l}\text { Single without children }=93(18.5) \text {; Single with children }=8 \\
(1.65) \text {; Couple without children }=38(7.6) \text {; Couple with children } \\
=360(71.65)\end{array}$ \\
\hline $\begin{array}{l}\text { Existence of a } \\
\text { private garden }\end{array}$ & Yes $=187(37.2) ;$ No $=316(62.8)$ \\
\hline $\begin{array}{l}\text { Attitudes to } \\
\text { religion }\end{array}$ & $\begin{array}{l}\text { Important }=223(44 \cdot 3) ; \text { Unimportant }=226(44.9) ; \\
\text { No answer }=54(10.7)\end{array}$ \\
\hline $\begin{array}{l}\text { The main source } \\
\text { of inspiration }\end{array}$ & $\begin{array}{l}\text { Christianity }=69(30.9) ; \text { Judaism }=2(0.9) ; \text { Islam }=7(3.1) \\
\text { Buddhism }=155(69.5) ; \text { Taoism }=36(16.1) ; \text { Other }=2(0.9) .\end{array}$ \\
\hline $\begin{array}{l}\text { Household income } \\
\text { per month ( вмв } ¥)\end{array}$ & $\begin{array}{l}<1,700=2(0.4) ; 1,700-3,900=16(3.2) ; 3,900-8,300=95(18.9) \\
8,300-16,600=238(47 \cdot 3) ;>16,600=148(29 \cdot 4)\end{array}$ \\
\hline
\end{tabular}

Note: The income classification was calculated by integrating the income in both rural and urban areas in China; data were from National Statistics Bureau in PRC (http://www.stats.gov .cn/) in 2014.

their companion animals, whereby a high score reflects strong attachment. Examples of questions include: "My pet understands my feelings"; "I miss my pet when I am not around"; and "My pet has feelings."

Finally, six primary (anger, joy [happiness], fear, surprise, disgust, and sadness) and four secondary (shame, jealousy, disappointment, and compassion) emotions (Ekman, 2003) were presented to the participants. They were asked whether they had witnessed these emotions expressed by their companion animals and if they thought that these animal emotions had been influenced by their own behavior (responsive emotions). Ratings were made on a 3 -point Likert-type scale $(1=$ never, 2 = sometimes, and $3=$ often $)$. The option of "No idea" was treated as missing data. 


\section{Procedure}

We conducted an online survey among a group of Chinese dog and/or cat caretakers with 557 people among a sampling frame of 3,006 people throughout the mainland of China in July 2015 by means of cluster sampling. Cluster sampling, a viable sampling design for collecting reference data, is often used when heterogeneous groupings are evident in a statistical population (Stehman, 1997). In order to keep the answers consistent, we asked respondents to report about only one dog or cat, even if they had several. For those caretakers having more than one companion animal, we required their responses to be based on the companion animal they had the longest (as did Martens et al., 2016).

\section{Statistical Analysis}

The correlation between respondents' attribution of (responsive) emotions and the degree of attachment to companion animals were analyzed with spss 24 statistical software. Given that the data in this study followed a normal distribution and the Levene test showed homogeneity of variances, a $t$-test was performed to investigate the differences between two groups, while a oneway ANOVA was carried out to investigate the differences across three or more than three groups. In order to reduce type-I errors due to repeated testing, the Fisher's procedure was employed in the analyses across three groups, and REGWQ correction was applied in the analyses across more than three groups. Pearson correlation analysis was conducted to investigate the correlations of the degree of attachment and the total score of emotion attribution to companion animals.

In order to know the difference between correlations for two groups, Fisher's $r$-to- $z$ transformation was performed. All results are based on two-tailed tests assuming equal variances; the values of $p<0.05$ were considered significant. Stepwise linear regression was used to relate the degree of caretaker attachment (measured by PBS) to some potential predictor variables. An alpha value of 0.05 was used for forward and backward regression of variables. All nonexplanatory variables were removed from the results in order to determine the optimum model (Martens et al., 2016; McDonald, 2014).

Notably, stepwise regression was regarded as problematic because it could result in the inappropriate selection of predictors, and this selection procedure might influence the final model (Derksen \& Keselman, 1992; James \& McCulloch, 1990). In order to address this problem and simultaneously reduce type-I errors, we only considered predictors appearing in the final model as influential variables (Petraitis, Dunham, \& Niewiarowski, 1996). Additionally, using this method may also increase type-II errors, but given the relatively 
large sample size in the present study, this risk should be reduced (Bradbury et al., 2000).

\section{Results}

\section{Which Emotions did Caretakers Attribute to their Companion Animals?}

Companion animals were perceived to frequently express the primary emotions of joy and surprise, while they were perceived to rarely express the primary emotions of disgust and sadness, and the secondary emotions of shame, jealousy, and disappointment (Table 2). We did not find any significant differences between the attribution of emotions for companion dogs and cats (with the exception of anger, which was more frequently attributed to companion dogs than cats).

\section{Does Gender or Age of Companion Animals Influence the Attribution of Emotions?}

Respondents who had a male dog, compared to those who had a female dog, were more likely to attribute surprise (for male dogs: $M=2.17, S D=0.72$; for female dogs: $M=1.94, S D=0.92 ; t(371)=2.68, p=0.01,=0.28)$ and compassion (for male dogs: $M=1.90, S D=0.88$; for female dogs: $M=1.64, S D=1.11 ; t(371)=$ $2.53, p=0.01,=0.26)$ to their companion animals. No significant differences in

TABLE 2 Attribution of emotions to companion animals

\begin{tabular}{lll}
\hline 1=never; 2=sometimes; $3=$ often & Mean & SD \\
\hline Anger & 1.87 & 0.57 \\
Joy & 2.87 & 0.40 \\
Sadness & 1.59 & 0.75 \\
Disgust & 1.49 & 0.79 \\
Fear & 1.90 & 0.64 \\
Surprise & 2.09 & 0.80 \\
Shame & 1.54 & 0.88 \\
Jealousy & 1.58 & 0.88 \\
Disappointment & 1.59 & 0.84 \\
Compassion & 1.81 & 0.99 \\
\hline
\end{tabular}


emotion attributions by caretakers were found according to either the gender or age group of companion cats.

\section{Does Gender or Age of Caretakers Influence the Attribution of Emotions to Companion Animals?}

Female respondents were more likely to attribute sadness (for female respondents: $M=1.70, S D=0.70$; for male respondents: $M=1.48, S D=0.79 ; t(501)=$ $3.25, p<0.01,=0.30$ ), jealousy (for female respondents: $M=1.68, S D=0.86$; for male respondents: $M=1.47, S D=0.88 ; t(501)=2.75, p<0.01,=0.24)$, disappointment (for female respondents: $M=1.67, S D=0.85$; for male respondents: $M=1.51, S D=0.82 ; t(501)=2.05, p=0.04,=0.19$ ), and compassion (for female respondents: $M=1.91, S D=0.96$; for male respondents: $M=1.70, S D=1.02$; $t(501)=2.37, p=0.02,=0.21)$ to their companion animals than male respondents. Disgust was more frequently attributed by respondents aged 18 to 49 years (for respondents aged 18-29 years: $M=1.53, S D=0.75$; for respondents aged 30-39 years: $M=1.52, S D=0.73$; for respondents aged 40-49 years: $M=1.53$, $S D=0.86)$ than those aged 60 years and older $(M=1.00, S D=0.65, F(4,498)=$ $2.76, p=0.03,=0.02)$, while disappointment was more commonly attributed by respondents aged 30 to 59 years (for respondents aged 30-39 years: $M=1.66$, $S D=0.74$; for respondents aged 40-49 years: $M=1.61, S D=0.87$; for respondents aged 50-59 years: $M=1.68, S D=0.87)$ than the 60 years and older group $(M=$ $1.16, S D=0.85, F(4,498)=2.51, p=0.04,=0.02)$.

\section{Demographic Correlates of the $\mathrm{PBS}$}

The average PBS score of all the respondents in this study was $78.25(S D=12.91)$ out of 100. Dog caretakers showed a higher attachment to their dogs $(M=79.22$, $S D=12.74)$ than cat caretakers did to their cats $(M=75.48, S D=13.03, t(501)=$ $2.86, p<0.01,=0.29)$.

\section{Companions of Dogs}

We considered 35 possible variables that might influence the PBs score, from the information we collected from dog caretakers (see Table 3 for influential variables). According to stepwise multiple regression analysis, the PBs score of respondents who were members of, or had donated to, an organization involved in improving human rights or health was 4.98 points higher than the respondents who did not. Caretakers who had a garden had a PBs score 2.98 points higher than those who did not.

The relationship between PBS scores and how respondents take care of their dogs showed that caretakers who liked watching their dogs had an average of 28.18 more points than those who did not. Respondents who considered 


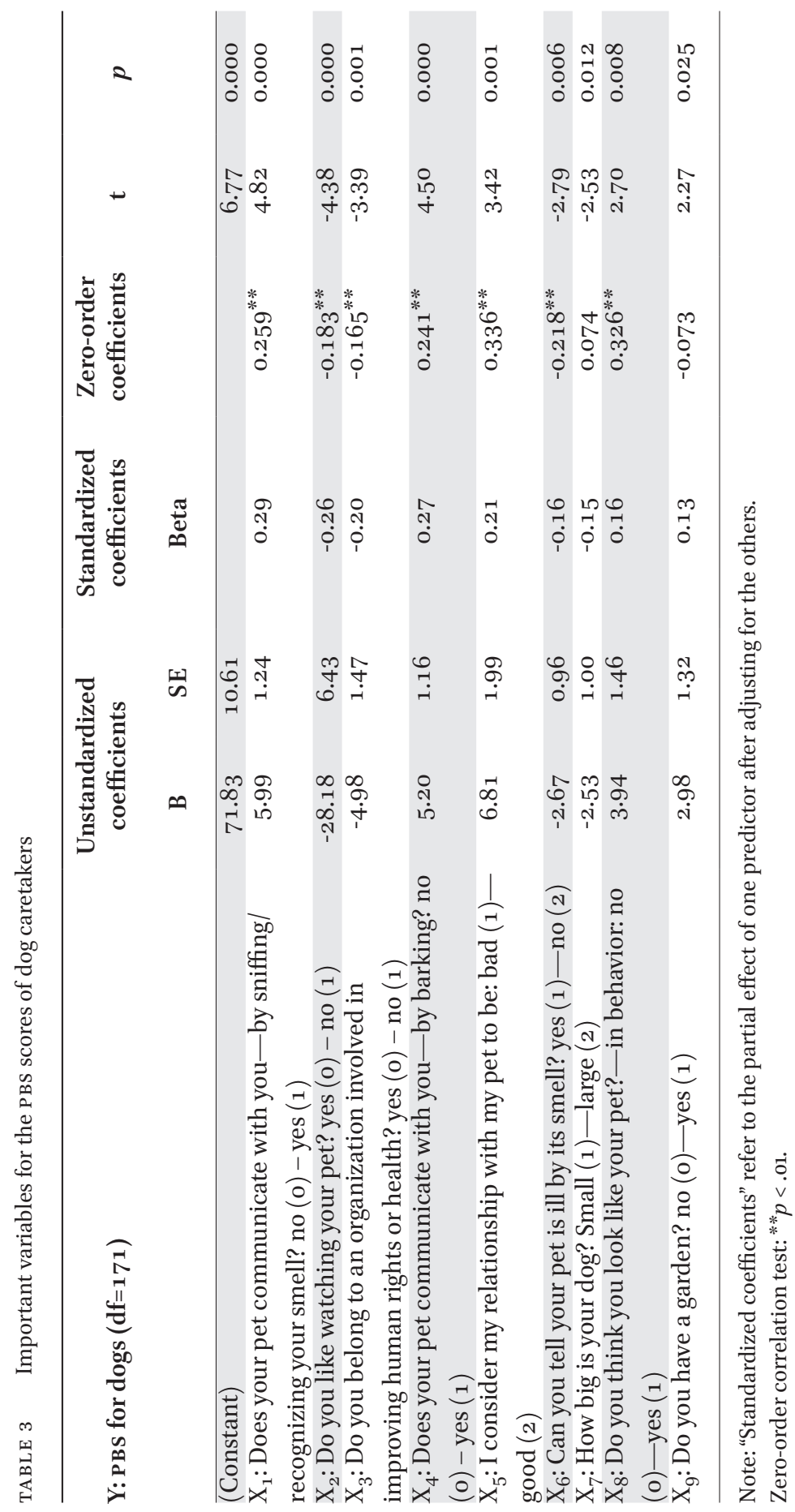


their relationship with their dogs to be "good" had a PBS score 6.81 points higher, on average, than those who felt they had a bad relationship. The average PBS score of respondents who thought their behavior looked like their dog had 3.94 more points than those who did not. Furthermore, the results also showed that those reporting that their dogs often communicated with them had higher scores than those who thought their dogs never communicated with them, and these differences were based on the different ways of interacting: 5.20 points by barking and 5.99 points by sniffing or recognizing their caretaker's smell. Caretakers who could tell their dog's illness by smell averaged 2.67 points higher than those who could not. Finally, the size of dogs was another correlation element influencing caretakers' attachments to their dogs. The average PBS score was 2.53 points lower for large companion dogs (more than $25 \mathrm{~kg}$ ) than for small dogs (less than $10 \mathrm{~kg}$ ) (Table 3 ).

\section{Companions of Cats}

Based on the relationships between the degree of attachment to companion cats and how caretakers take care of them, as well as caretakers' demographics variables (see Table 4), we noticed that caregivers who agreed that they looked like their cat in behavior had 19.16 points higher on the Рвs score than those who did not. Respondents who were the main caregiver of companion cats averaged 19.03 points above those who were not the main caregiver of their cats.

Furthermore, respondents who thought that their cats communicated by looking at them averaged 8.36 points higher than those who did not think their cats communicated in this way. The PBS score of respondents who gave their cats more than 50 grams of food each day had 6.97 more points than those who fed less than 50 grams per day. Caretakers who used shelters or kennels to take care of their cats when they were not around scored 7.48 points higher than those who did not. Household composition was another factor that influenced the PBS scores of cat caretakers, such that the score of respondents who were single/couple with children was on average 8.35 points higher compared to respondents who were single/couple without children (Table 4).

\section{Is there a Correlation between the Degree of Attachment (Overall PBS Score) and the Attribution of Emotions to Companion Animals?}

There was a significant correlation between caretakers' degree of attachment (measured by Рвs score) and their attribution of sadness, surprise, shame, jealousy, or compassion to companion animals (all $p<0.05$ ). Furthermore, our results also indicated significant correlations between the degree of attachment and female caretakers' attribution of surprise, shame and compassion (all $p<0.05$ ). For male caretakers, this correlation was significant for 


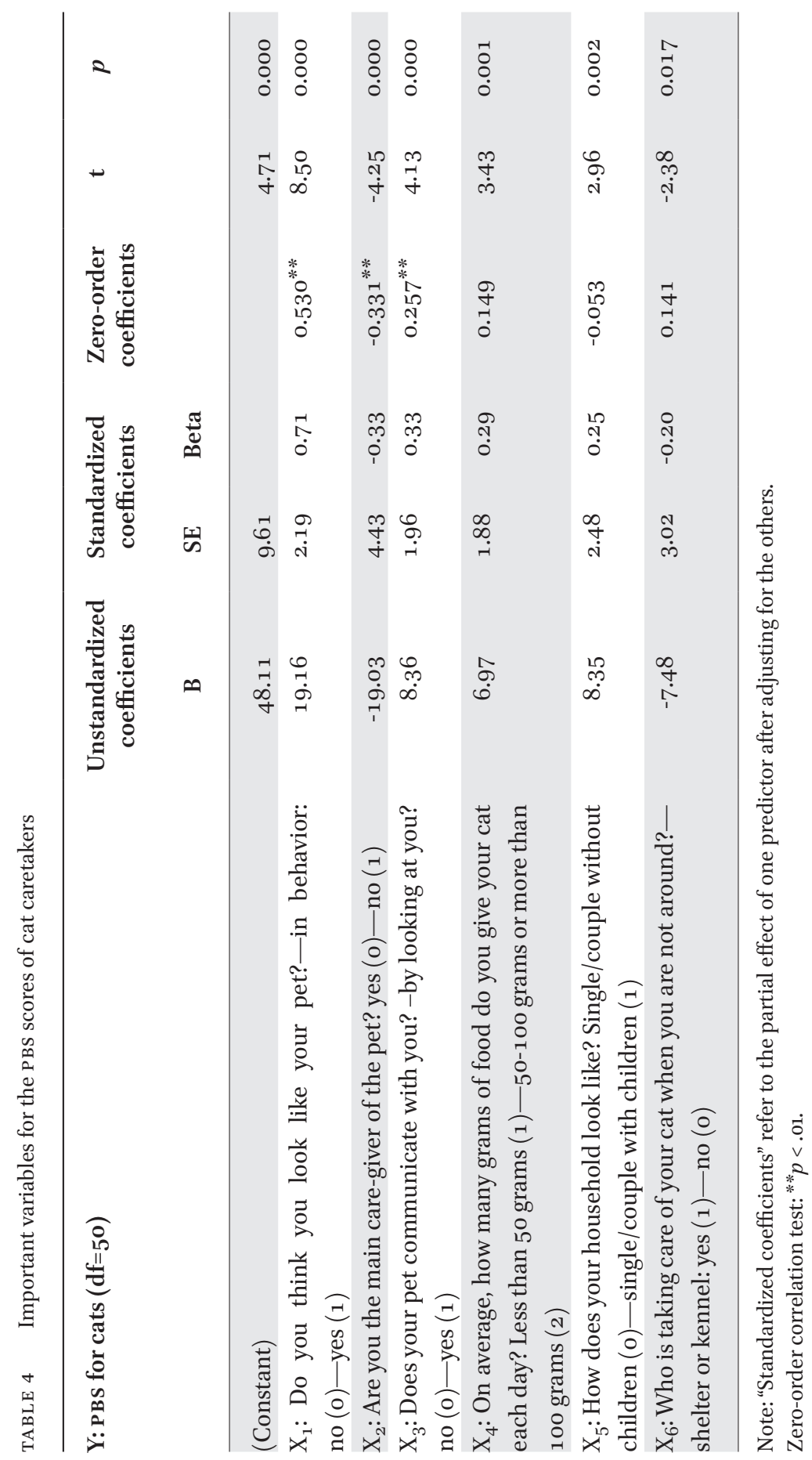


the attribution of sadness, jealousy and compassion (all $p<0.05)$. The correlations between dog caretakers' degree of attachment and their recognition of sadness, surprise, shame, and compassion in their dogs were found to be significant (all $p<0.05$ ), while for cat caretakers, this correlation was significant for joy, surprise, and compassion (all $p<0.05$ ) (see Table 5 for correlation coefficients).

Based on the results of Fisher's r-to-z transformation, we found that correlations between the degree of attachment and attributions of emotions did not differ greatly between the male and female caretakers (with the exception of surprise, $p<0.05$ ) or between dog and cat caretakers (with the exception of joy, $p<0.05)$.

\section{Is there a Correlation between the Degree of Attachment (Overall PBS Score) and the Attribution of Responsive Emotions to Companion Animals?}

The overall relationship between caretakers' degree of attachment (measured by PBS score) and the attribution of responsive emotions was statistically significant for anger, joy, surprise, shame, jealousy, disappointment, and compassion (all $p<0.05$ ). Additionally, significant correlations were also found between caretakers' degree of attachment and the attribution of the responsive emotions of joy, shame, jealousy, and compassion to companion cats (all $p<0.05$ ). For dogs and their caretakers, this correlation was significant only for the attribution of surprise and compassion (all $p<0.05)$. The relationship between female caretakers' degree of attachment and their attribution of responsive emotions to companion animals was significant for joy, surprise, shame, jealousy and compassion (all $p<0.05$ ), while this correlation was significant only for anger $(p<0.05)$ in male respondents (see Table 5 for correlation coefficients).

\section{Discussion}

The aim of this study was to investigate Chinese companion animal caretakers' attribution of their animals' emotions, as well as what influence their degree of attachment has on this emotion attribution. The results indicate that the degree of caretakers' attachment significantly influenced their attribution of some certain (responsive) emotions onto companion animals. This finding is in accordance with previous studies conducted in developed countries (Hare \& Woods, 2013; Martens et al., 2016; Rizzolatti, Fogassi, \& Gallese, 2001), although the awareness of animal welfare of people in developed countries is 


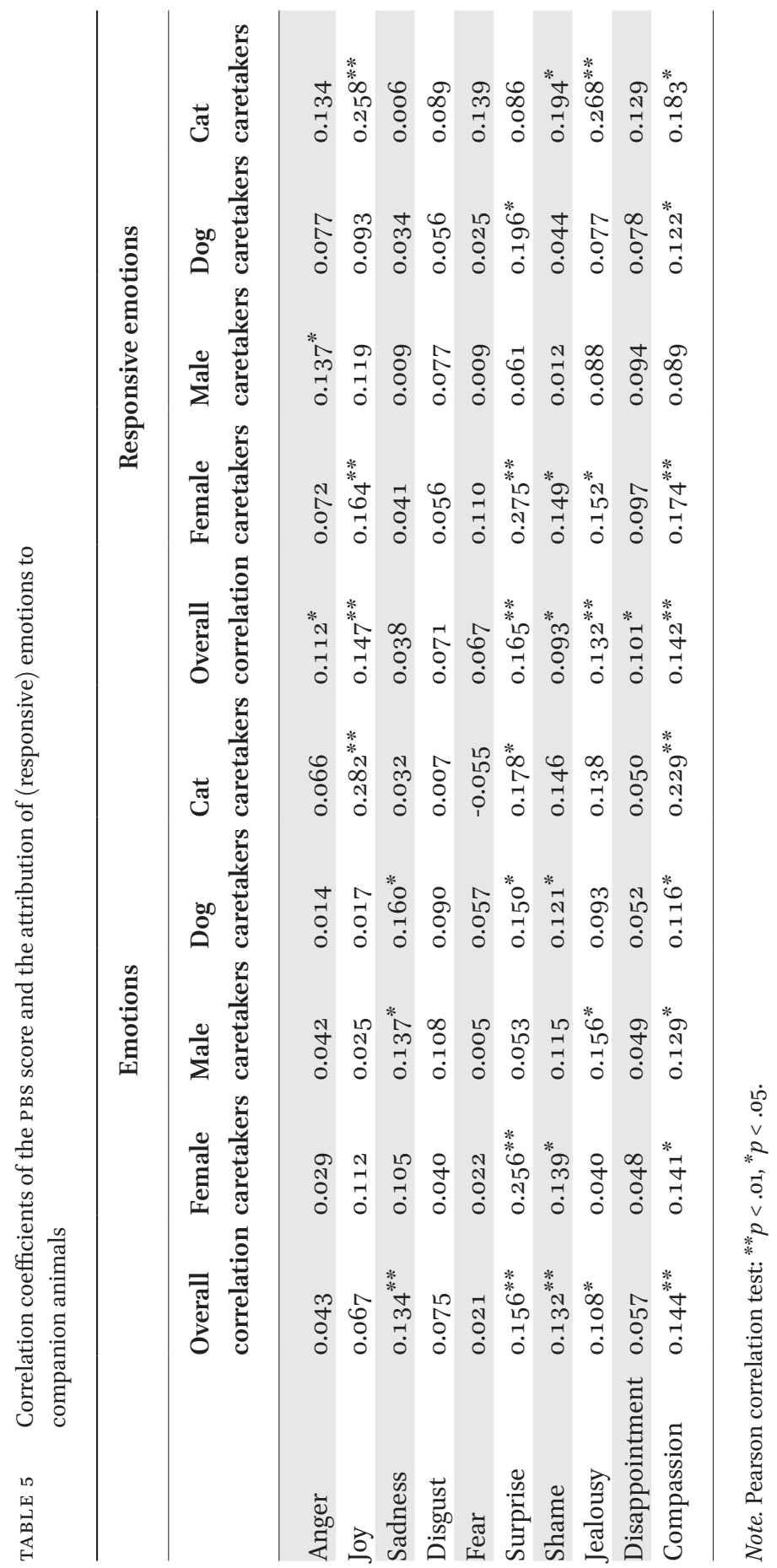


higher than that of Chinese people. One possible explanation for this similar result might be that Chinese people's contemporary understanding of animal emotions stems from their philosophical traditions ranging from Taoism to Buddhism, in which animal is regarded as an essential component of nature and generally has the same feeling as humans (Li \& Davey, 2013).

\section{Emotions Attributed and Species Differences}

Our results suggest a trend that respondents frequently attributed primary emotions to companion animals rather than secondary emotions, confirming that primary emotions were more easily attributed by caretakers. This finding parallels the results of an earlier study by Morris et al. (2008), who proposed that primary emotions were experienced more frequently than secondary emotions among companion animals. Our results also reveal that the secondary emotion of compassion was frequently attributed by our respondents, which is inconsistent with earlier findings by Martens et al. (2016), who reported that respondents commonly attributed the secondary emotion of jealousy to their companion animals. One possible reason is that compassion is often regarded as an essential component of spiritual attitudes, which derives from Chinese cultural traditions of Confucianism and Buddhism (Fam, Waller, \& Erdogan, 2004). It is therefore plausible that caretakers may think their animals can express such emotion.

Additionally, in order to decrease the number of stray dogs, only one dog per household was allowed in some cities (e.g., Qingdao) of China. However, many families in developed countries have more than one dog or cat (Grier, 2010; Sussman, 1985), and jealousy often occurs between two or more animals (Tam \& Smith, 2014), so it is not surprising that jealousy is attributed frequently to companion animals in developed countries.

Our results demonstrate that the sex of companion dogs influenced respondents' attribution of surprise and compassion to their dogs, although the age of companion dogs did not influence respondents' attribution of emotions to them. We found no difference in how caretakers attribute emotions to companion cats, according to cats' gender or age, which is in contrast to a previous study (Marinelli et al., 2007) showing that an animals' age could influence the emotional interactions between companion animals and caretakers. Possibly, the lack of evidence for this association in our results might be explained by the lower number of cat caretakers.

\section{The Influence of Caretaker Demographics}

Consistent with recently published work by Martens et al. (2016), who reported that companion animal caretakers recognized primary and secondary 
emotions of their companion animals, our results also demonstrate that many companion animal caretakers witnessed their animals' different emotions. Around half of the respondents showed positive attitudes to religions (particularly Buddhism), and more than half of the respondents had experiences of improving animal welfare or the natural environment, which means that they have more direct access to the information and knowledge of animals and animal emotions shared in their doctrines or communities. This may also contribute to their recognition of animal emotions. Additionally, our findings imply that most of the secondary emotions were more frequently attributed by female caretakers than male caretakers (as did Walker, McGrath, Nilsson, Waran, \& Phillips, 2014). One explanation is that males may not have learned to express or recognize emotions as clearly as females (Brody, 1985) and the other is that sex differences do vary markedly across different emotion studies (Stevens \& Hamann, 2012). Our findings also demonstrate that respondents' age played a role in influencing their recognition of animal emotions of disgust and disappointment: the older the person, the lower the level of the perception of disgust and disappointment. This might be caused by the fact that animal emotion is a new research topic in China. Therefore, younger generations are more aware of it, while older generations tend to view the utilitarian values of animals as more important than animal emotions. This finding supports the expectations of differences in emotional recognition between old and young people (Sze, Goodkind, Gyurak, \& Levenson, 2012).

\section{Determinant Variables of the PBS}

A further aim of this study was to figure out which variables determined people's degree of attachment to their companion animals. Our findings demonstrate that dog caretakers were more attached to their dog than cat caretakers to their cat, which may be explained by the higher level of mutual understanding between humans and dogs, compared to that of humans and cats (Bekoff, 2005). Another interesting finding was that caretakers with a private garden had a higher level of attachment to their animals than those who did not. This might be due to the fact that most of these caretakers were housewives from wealthy families in China, and they had more time to interact with their animals, which could accelerate their mutual understanding and foster good relationships (Fox \& Gee, 2016; Woodward \& Bauer, 2007). Additionally, our results reveal that respondents who were living with their children had a higher level of attachment to their animals than those without children. One possible explanation would be that parents living with children would have more knowledge of animals to satisfy their children's appetite for knowledge. Furthermore, it is plausible that small animals have less demand (e.g., food) 
than large animals. Therefore, it is not surprising that in our research, respondents who had a small dog showed a higher level of attachment to their dogs than respondents who had a large dog.

\section{Caretaker Attachment and Attribution of Emotions}

Our investigations indicate the existence of significant correlations between respondents' attachment level and their attribution of certain emotions to their companion animals. These correlations were not very strong, although a higher level of attachment was related to caretakers having a stronger willingness to attribute several emotions to companion animals. These results may due to the long-standing neglect of animal welfare in China, although Chinese people culturally consider animals as important and their awareness of animal welfare has indeed increased in the past two decades (Littlefair, 2006).

Probably due to sampling error, we found that the correlation between the degree of attachment and the attribution of emotions to companion animals did not differ greatly between either male and female caretakers, or dog and cat caretakers, which is partly in accordance with a study reporting that respondents' gender was not a significant factor in influencing the relationship between attachment level and emotional attribution to companion animals (Martens et al., 2016). Additionally, the correlations between dog caretakers' attachment level and their attribution of shame and sadness to their dogs were significant, while we did not find such correlations among cat caretakers. Given the relative limited number of cat caretakers in this study $(25.8 \%)$, this finding needs to be viewed with caution.

\section{Caretaker Attachment and Attribution of Responsive Emotions}

The results indicate that respondents who attributed emotions to their animals generally believed that their behaviors could influence their animals' emotions, which confirms the findings by Martens et al. (2016). Our and Martens et al.'s research reveals that interspecies understanding and responsive emotions might exist, such as between humans and nonhuman animals. Significant positive correlations between the degree of attachment and the attribution of six out of ten responsive emotions exist among female respondents, suggesting that female caretakers may have a high sensitivity for responsive emotions. One possible explanation is that women have high levels of belief in the mental abilities of animals (Knight et al., 2003).

\section{Limitations of this Study}

Although the present research gained some insights by measuring caretakers' degree of attachment to companion animals, several sources of error exist in this study. For instance, due to the information collection method, unbalanced 
distributions existed among the participants (e.g., the number of dog caretakers was approximately three times higher than cat caretakers). This may have influenced the number of insignificant differences found in certain results. In addition, the sample population is a cluster sample that may not accurately represent the general Chinese population.

\section{Conclusion}

The present study followed a similar approach to that of previous studies conducted in developed countries (Mariti et al., 2012; Martens et al., 2016; Morris et al., 2008). All these studies indicate that companion animal ownership or the degree of attachment can influence the attribution of emotions to companion animals. In addition, many studies (Darwin, 1965; Martens et al., 2016; Morris et al., 2008) have demonstrated that animal species played a central role in influencing respondents' attribution of emotions to companion animals in developed countries (e.g., respondents were more likely to attribute some emotions to their dogs than cats), while in the present Chinese study, the influence of animal species was very small. This may be due to the different levels of animal welfare between developed and developing countries. Compared to the populations in developed countries, most of the Chinese people have a lower awareness of animal welfare. Another possible explanation is that in Chinese culture, people's attitudes toward dogs and cats are not significantly different, as both animals stand for good things: for example, the dog is the symbol of loyalty, while the cat represents wealth.

Findings from the present study imply that Chinese companion animal caretakers have a high attachment to their animals, which means that a good relationship between companion animals and their caretakers exists in contemporary China. This research represents a positive step towards advancing the topic of animal welfare, as a higher attachment to companion animals may lead to a better understanding of animal protection and a higher awareness of animal welfare. Therefore, identifying the emotional relationships between companion animals and their caretakers, and eventually promoting the development of an optimal animal welfare measurement system in China, are the main goals for any future studies we conduct in this area of research.

\section{Questionnaire}

The questionnaire is available via the URL: https://figshare.com/s/ $360 f 70 b 928$ ofoeac71cb. 


\section{Acknowledgments}

We acknowledge the effort of Flycatcher for their help with the data collection. We thank all the dog and cat caretakers for their participation in the survey. B.S. is funded by Chinese Scholarship Council (CSC) (Grant no. 201406300005).

\section{References}

Anderson, D. C. (2007). Assessing the human-animal bond: A compendium of actual measures. West Lafayette, IN: Purdue University Press.

Angle, R., Blumentritt, T., \& Swank, P. (1994). The Pet Bonding Scale: Internal reliability and factorial validity. Paper presented at the Annual Meeting of the Southwestern Psychological Association, Tulsa.

Barber, S. (2015). Nonhuman animal welfare in China: Evolving rhetorical strategies for changing law and policy.Journal of International Wildlife Law \& Policy, 18(4), 309-321.

Becker-Asano, C., \& Wachsmuth, I. (2010). Affective computing with primary and secondary emotions in a virtual human. Autonomous Agents and Multi-Agent Systems, 20(1), 32-49.

Becker, C., \& Wachsmuth, I. (2006). Modeling primary and secondary emotions for a believable communication agent. Paper presented at the Proceedings of the 1st Workshop on Emotion and Computing.

Bekoff, M. (2005). Animal passions and beastly virtues: Reflections on redecorating nature. Philadelphia, PA: Temple University Press.

Blakeley, D. N. (2003). Listening to the animals: The Confucian view of animal welfare. Journal of Chinese Philosophy, 30(2), 137-157.

Bradbury, R. B., Kyrkos, A., Morris, A. J., Clark, S. C., Perkins, A. J., \& Wilson, J. D. (200o). Habitat associations and breeding success of yellowhammers on lowland farmland. Journal of Applied Ecology, 37(5), 789-805.

Brody, L. R. (1985). Gender differences in emotional development: A review of theories and research. Journal of Personality, 53(2), 102-149.

D'Silva, J., \& Turner, J. (2012). Animals, ethics and trade: the challenge of animal sentience. London, United Kingdom: Routledge.

Darwin, C. (1965). The expression of the emotions in man and animals. The American Journal of the Medical Sciences, 232(4), 477.

Davey, G. (2006). Chinese university students' attitudes toward the ethical treatment and welfare of animals. Journal of Applied Animal Welfare Science, 9(4), 289-297.

Derksen, S., \& Keselman, H. (1992). Backward, forward and stepwise automated subset selection algorithms: Frequency of obtaining authentic and noise variables. British Journal of Mathematical and Statistical Psychology, 45(2), 265-282. 
Ekman, P. (2003). Darwin, deception, and facial expression. Annals of the New York Academy of Sciences, 1000, 205-221.

Fam, K., Waller, D. S., \& Erdogan, B. (2004). The influence of religion on attitudes towards the advertising of controversial products. European Journal of Marketing, $38(5 / 6), 537-555$.

Fox, R., \& Gee, N. R. (2016). Changing Conceptions of Care. Society \& Animals, 24(2), 107-128.

Grier, K. C. (2010). Pets in America: A history. Chapel Hill, NC: UnC Press Books.

Hare, B., \& Woods, V. (2013). The genius of dogs: how dogs are smarter than you think. London, United Kingdom: Penguin.

James, F. C., \& McCulloch, C. E. (1990). Multivariate analysis in ecology and systematics: panacea or Pandora's box? Annual Review of Ecology and Systematics, 21, 129-166.

Knight, S., Nunkoosing, K., Vrij, A., \& Cherryman, J. (2003). Using grounded theory to examine people's attitudes toward how animals are used. Society \& Animals, 11(4), 307-327.

Kobak, R. (2009). Defining and measuring of attachment bonds: Comment on Kurdek. Journal of Family Psychology, 23(4), 447-449.

Li, P. J., \& Davey, G. (2013). Culture, reform politics, and future directions: A review of China's animal protection challenge. Society \& Animals, 21(1), 34-53.

Littlefair, P. (2006). Why China is waking up to animal welfare. Animals, Ethics and Trade: The Challenge of Animal Sentience, 225-237.

Marg, E. (1995). Descartes' error: emotion, reason, and the human brain. Optometry \& Vision Science, 72(11), 847-848.

Marinelli, L., Adamelli, S., Normando, S., \& Bono, G. (2007). Quality of life of the pet dog: Influence of owner and dog's characteristics. Applied Animal Behaviour Science, $108(1-2), 143-156$.

Mariti, C., Gazzano, A., Moore, J. L., Baragli, P., Chelli, L., \& Sighieri, C. (2012). Perception of dogs' stress by their owners. Journal of Veterinary Behavior: Clinical Applications and Research, 7(4), 213-219.

Martens, P., Enders, M. J., \& Walker, J. (2016). The emotional life of companion animals: Attachment and subjective claims by owners of cats and dogs. Anthrozoös, 29(1), $73-88$.

McDonald, J. H. ( 2014). Handbook of biological statistics, 3rded. Baltimore, MD: Sparky House Publishing.

Morris, P., Doe, C., \& Godsell, E. (2008). Secondary emotions in non-primate species? Behavioural reports and subjective claims by animal owners. Cognition \& Emotion, 22(1), 3-20.

Petraitis, P., Dunham, A., \& Niewiarowski, P. (1996). Inferring multiple causality: The limitations of path analysis. Functional Ecology, 10(4), 421-431.

Pręgowski, M. P. (2016). Companion animals in everyday life. Berlin, Germany: Springer. 
Preston, S. D., \& De Waal, F. (2002). Empathy: Its ultimate and proximate bases. Behavioral and Brain Sciences, 25(1), 1-20.

Rizzolatti, G., Fogassi, L., \& Gallese, V. (2001). Neurophysiological mechanisms underlying the understanding and imitation of action. Nature Reviews Neuroscience, 2(9), 661-670.

Stehman, S. V. (1997). Estimating standard errors of accuracy assessment statistics under cluster sampling. Remote Sensing of Environment, 6o(3), 258-269.

Stevens, J. S., \& Hamann, S. (2012). Sex differences in brain activation to emotional stimuli: A meta-analysis of neuroimaging studies. Neuropsychologia, 5o(7), 1578-1593.

Sussman, M. B. (1985). Pets and the family. East Sussex, United Kingdom: Psychology Press.

Sze, J. A., Goodkind, M. S., Gyurak, A., \& Levenson, R. W. (2012). Aging and emotion recognition: Not just a losing matter. Psychology and Aging, 27(4), 940.

Tam, N. D., \& Smith, K. M. (2014). Cognitive computation of jealous emotion. Psychology and Behavioral Sciences, 3(6-1), 1-7.

Walker, J., McGrath, N., Handel, I., Waran, N., \& Phillips, C. (2014). Does owning a companion animal influence the belief that animals experience emotions such as grief? Animal Welfare, 23(1), 71-79.

Walker, J., McGrath, N., Nilsson, D. L., Waran, N., \& Phillips, C. (2014). The role of gender in public perception of whether animals can experience grief and other emotions. Anthrozoös, 27(2), 251-266.

Waller, B. M., \& Micheletta, J. (2013). Facial expression in nonhuman animals. Emotion Review, 5(1), 54-59.

Walsh, F. (2009). Human-animal bonds I: The relational significance of companion animals. Family Process, 48(4), 462-480.

Woodward, L. E., \& Bauer, A. L. (2007). People and their pets: A relational perspective on interpersonal complementarity and attachment in companion animal owners. Society \& Animals, 15(2), 169-189. 